\title{
Rhetoric in Retreat (The Good, the Bad, and the Ridiculous)
}

\section{Some Serious Semantics}

Nothing is more apt to insult someone than fun-poking around issues important to a subgroup of humankind-whether circumscribed by ethnicity, gender, height, weight, etc. "Posterminaries" hazards into this linguistic no man's or woman's land because too often we see language squirm self-consciously in stilted phraseology as it tries to navigate from guidepost to guidepost along boundaries demarcating good taste from offense. (This article itself is a prime example.) For the mine field ahead, it would be nice to apply the eloquence of a poet, the incisiveness of a surgeon, the diplomacy of a statesperson, and the wisdom of a sage. We must, however, settle for the hamhandedness (no porcine offense intended)' of this scribe.

\section{Divergence of the Ds: (Good)}

How do we recognize and describe diversity, a quality both humankind and language enjoy? We can be distinguished, differentiated, discriminated, and diversified. Being distinguished is still $\mathrm{OK}$, and as yet carries no baggage of inequity. Differentiation is also still OK in calculus and, in a technical biological sense, it is the very process through which our traits are determined. It has escaped both positive and negative implications.

To be discriminating smacks of an acceptable level of snobbish selectivity when applied to food, wine, literature, and perhaps automobiles. However, discrimination, per se, as applied to species Homo sapiens, has fallen into disrepute and is ethically, morally, and in many cases legally bankrupt. It is a dangerous term. A purist might protest that false impressions of unfairness are the listeners' problem, but that purist has probably never encountered the real thing. Such evolutionary differentiation among formerly synonymous terms is how language remains alive and diverse of nuance. Diversification itself has gone beyond being good for language and investment portfolios. The same social awareness that damaged discrimination has deified diversity in the cultural context. In general, we have plenty of words to spare for evolution.

\section{Sexual Semantics or the Ultimate $D$ Fence: (Bad)}

The assertion is made that defaulting to the male pronoun as generic both legitimates the status quo and perpetuates stereotypes. It is therefore a factor itself in entrenching bias. Language is at once both villain and victim. Gender bias has therefore created the worst conundrum for the grammarian in the workplace.

This is particularly hazardous territory where, to borrow Koshland's ${ }^{2}$ words, only angels and editors would venture and wise men [sic] fear to tread. Why? Because juxtaposing the immense issue and fact of bias against the disadvantaged majority with an apparently inconsequential choice of pronoun for ideologically correct speech risks both trivializing the significant and overemphasizing the trivial, to everyone's dismay. Nevertheless, we forge ahead.

"Generic he has disappeared from most scientific publications, after a fierce fight. . . F Further work awaits the linguistic reformer, for in this hard-fought battle, pronouns are but prelude," according to Anne Eisenberg. ${ }^{3}$ Although a speaker's "or she," self-consciously appended to a "he," can be greeted with empathetic grins, and even though it is healthy not to take ourselves too serious$1 y$, there is something less than funny here. Strings of gender-presumptive usages represent micro-inequities which sum to substantive discounts of the omitted sex. Thus the battle has been joined.

Before Degenderization truncates all chairmen and chairwomen to chairs and all spokesmen and spokeswomen to spokes, before it replaces more charwomen and mailmen with cleaners and carriers, before it neuters ${ }^{4}$ another suffix with an impartial "-person," you should visit your own personal pronounbefore its complete eradication. These decades of heightened awareness may be labeled by future linguists as the "Age of Antecedent Resurgence," when repetition is deemed the lesser evil, when such noncommittals as "the person" or "the individual" reign, and when gender-specific pronouns are relegated to the domain of the novelist, along with their sister epithets and brother expletives. Then again, it may be premature to count our pronouns out.

\section{Transgression Become Tool: (Saving Grace)}

Our beloved he and she will continue to be used when we know the gender of a specific antecedent. When Vogue magazine ${ }^{5}$ poses 24 congresswomen and congresswomen-elect for a group photograph, the very quest for equality demands retention of gender in language.

During the evolution toward equality, the counter-presumptive use of pronouns becomes a forceful form of rhetoric. The more subtle examples are perhaps the most instructive. A flattering letter to Science from Debra R. Rolison et al. ${ }^{6}$ about the magazine's coverage of the women-in-science issue begins, "We commend Science and her [sic] editors and staff..." When common usage for an inanimate object does not demand a gender, its unnecessary introduction makes

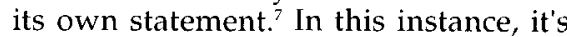
more than old-fashioned anthropomorphization imputing presumably positive feminine characteristics to a magazine. It raises the whole degenderization specter. Not bad for a puny pronoun!

In outer space, degenderization has relaxed a bit too. Outer space had been a place where "no man has gone before." The empty set was subsequently augmented to "a place no one has gone before." ${ }^{4}$ It was a reassuring verification that women found outer space as difficult to reach as men did. Gender has crept back in recently, at least as far as our own solar system is concerned. NASA's Project Magellan is sponsoring a contest $^{10}$ to name new features of Venusian terrain after famous dead women because Venus is/was the goddess of love. Even though we may still not let an astronomer-author refer to Venus as she, this is a graceful way to redress the eight-to-one gender gap of the planets and we applaud the return of Rome-ance to the stars.

In the thick of the degenderization battle, the gender defender is prone to hurl a rational argument at you. Beware! Just as 
rational numbers do not alone fill the number line, more than rational discourse is required to enlighten the gender-bias blind. And, rationalizations can masquerade as rational arguments that are particularly ridiculous when spewed forth from an over-intellectualized technical mind. We offer below a handy crib sheet for such encounters.

\section{Ridiculous Rationalizations}

\section{The Argument of the Biological Imperative}

Let's face it! Biological differences persist, even in the 90s. (This is the wrong publication for us to toss in the trite, gratuitous, and-some feel-obligatory "vive la $D$..." cliché.) Their influence on and mention in the equity arenas should vanish. Surely they will need reference in other contexts. Let us not have the debate here over inherited versus environmentally acquired traits. Suffice it to say that to the extent personalities and approaches to life, including work, vary by gender, any profession must benefit from androgyny and there ought to be an acceptable way to talk about it, even if he and she must be used. (The terms Yin and Yang could be dispensed with only if our pronouns could be rehabilitated.)

\section{Literary License}

We have already exempted the content of novels (at least those targeted at postcareer-choice consenting adults). This doesn't let language off the hook altogether. But if the poet's distinction between the feminine and masculine rhyme, as in Mother Nature and Father Time, based on unstressed versus stressed final syllables of a line, can survive because gender textures do differ, may we not extrapolate this largesse to our beleaguered pronouns in unpoetic speech? Let us have our she-magazines and he-magazines. (The Bulletin, of course, remains neither or both, as the circumstances demand.)

\section{The Accident of English Argument}

Supposedly we speakers of English should be grateful that all of our nouns and articles do not carry gender. Some thought could be given to correlations between male/female parity and genderbased syntax (and politeness require- ments) in societies with languages that do. After all, if in societies where such blatant gender bias in language exists, the detrimental effects on one sex or the other cannot be proven, why should English be singled out for pronoun bludgeoning. Until the jury is in (and it has yet to be impaneled), we can assume San José and Santa Anita are safe; Las Vegas may be in trouble and Koshland's angels, with whom we are soul mates here, will certainly not take kindly to renaming Los Angeles.

\section{The Quantum Statistical Argument}

Let $\mathrm{G}$ be the gender operator with eigenstates $|m\rangle,|f\rangle$ and $|n\rangle$ and corresponding eigenvalues $m, f$, and $n$. Let $|\mathrm{r}\rangle$ be the wavefunction describing the role of an object. All inanimate objects are degenerate with respect to $G$, with $\mathrm{G} \mid$ thing $\rangle=n \mid$ thing $\rangle$. Some animate $|r\rangle s$ are also eigenstates of $G$. For example $\mathbf{G}$ | natural mother $\rangle=f \mid$ natural mother $\rangle$. In most cases, however, an animate $|r\rangle$ must be expanded as $R_{m}|m\rangle+$ $R_{\mathrm{f}}|\mathrm{f}\rangle$. When a measurement is carried out on a particular physical system, $|r\rangle$ is forced into an eigenstate of $G$. The probable outcome is the expectation value $\langle\mathbf{r}|\mathbf{G}| \mathrm{r}\rangle=m \mathrm{R}_{\mathrm{n}}^{2}+f \mathrm{R}_{\mathrm{f}}^{2}$. It is therefore valid, in the absence of a direct measurement, to use the pronoun (s)he when $\left|R_{\mathrm{f}}\right|(>)<\left|R_{\mathrm{m}}\right|^{*}$ (This approach assumes that the quantum mechanical expectation value and the societal value of the expectation are identical.)

\section{The Massively Parallel Argument}

At one time, it was supposed that a branch point would stop a parallel computation dead in its tracks. That is, one could not proceed down any branch that depended on the alternative values of the quantities computed at the branch point. So lots of time would be wasted by most processors awaiting the decision. It turns out that most branch points favor one particular outcome far more than another. Therefore, modern ap-
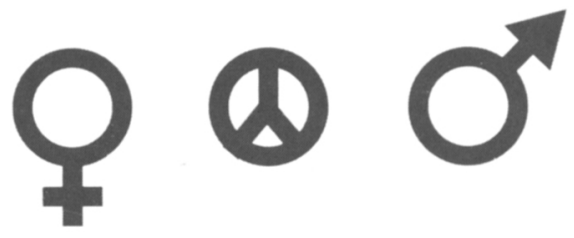

Peaceful coexistence proaches recognize that huge efficiencies can be achieved if one calculates past the branch point, assuming the most likely outcome, and goes back to fix the mistake the few times the unlikely one occurs. Is it not then entirely reasonable in speech, for the sake of efficiency, to use he or she according to the most likely gender for, e.g., the unknown nurse, chef, astronaut or bank president, until one discovers the choice to be wrong?

\section{The Bias is Beautiful Thesis}

This one is much like the "four Ds" dispensed with above, but goes further. That is, "bias" does not necessarily imply unfairness. And the argument posits that bias is a necessary factor in progress. Much as no electric current flows in an unbiased circuit, so does no social progress happen without gradients that disrupt the status quo. (That this seems always an uphill battle leaves us with a nagging sign error somewhere.)

Readers with additional examples are encouraged to send them to $M R, M S$, or MRS Bulletin, as appropriate.

\section{E.N. KAUFPERSONN}

\begin{abstract}
*We are neglecting the possibility of nonconservation of gender through such surgical transition matrix elements as $\langle\mathrm{m}|\mathrm{S}| \mathrm{f}\rangle \neq 0$.
\end{abstract}

\section{References}

1. Pork of the congressional variety is, however, not exempted from the barb.

2. D.E. Koshland Jr., "Minorities in Science" (editorial), Science 258 (13 November 1992) p. 1067.

3. A. Eisenberg, "Women and the Discourse of Science" (essay), Scientific American (July, 1992) p. 22 4. Strangely, "neuter" is the masculine form of the adjective (neuter, neutra, neutrum) meaning "neither (of two)." The default English gender for no gender at all is apparently male.

5. As reported in USA Totay, December 1, 1992, p. $4 \mathrm{~A}$.

6. Debra R. Rolison, Patricia A. Thiel, Angelica M Stacy, Geraldine L. Richmond, Jane K. Rice, Jeanne E. Pemberton, Janet G. Osteryoung, William E. O'Grady, Robert J. Nowak, and Robert L. Lichter, Science 256 (19 June 1992) p. 1614.

7. Even subtler is the nonalphabetical order in which co-authors in Reference 6 are listed.

8. "Star Trek," the television series of the mid- to late 1960s.

9. "Star Trek: The Next Generation," the television series of the late $1980 \mathrm{~s}$

10. Vemus Names, Magellan I'roject Office, Mail Code 230-201, Jet Propulsion Laboratory, 4800 Oak Grove Drive, Pasadena, CA 91109. 